\title{
Implication of Vitamin D Deficiency on Autoimmune Disorders
}

\author{
Dr. Pushpamala Ramaiah ${ }^{1}$, Dr. Ayman Johargy ${ }^{2}$, Dr. Lamiaa Ahmed Elsayed ${ }^{3}$ \\ ${ }^{1}$ Professor at Faculty of Nursing, Umm-Al-Qura University, KSA \\ ${ }^{2}$ Associate professor of Medical Microbiology, Faculty of Medicine, Umm Al-Qura University \\ ${ }^{3}$ Associate professor at Faculty of Nursing, Umm-Al Qura University, Makkah, KSA \\ Professor of Pediatric Nursing Faculty of Nursing. Ain Shams University, Egypt
}

\begin{abstract}
Vitamin D deficiency is now being recognized as a common public health issue worldwide. Studies have found that maintaining vitamin D status may reduce ones risk of developing various diseases. The core objective of this review article is to reveal the significance of vitamin D\& immune disorderin the regulation of normal physiology as well as the consequences of its deficiency, which is the need of the hour to save the population from widespread bone and other vitamin D deficiency disorder. Adequate vitamin D could regulate the calcium and phosphorous absorption to maintain healthy bones, teeth, and is suggested to supply protective effect against multiple diseases and conditions later in their life, such as cancer, type 1diabetes and multiple sclerosis, because evidence has shown that vitamin D could have lifelong health benefits. There is urgent need to prioritize development of national level program to make available, quality regulated and affordable vitamin $D$ supplementation and vitamin $D$ fortified foods.
\end{abstract}

Keywords: Vitamin D, Autoimmune Disorders, Protective immunity, Daily allowances of Vitamin D, lifestyle changes.

\section{Introduction}

Vitamin D is a group of fat soluble steroids which aid in the absorption of calcium and phosphate by the intestine. Our body can synthesize Vitamin D with adequate exposure to sun. Vitamin D deficiency is widespread and has been associated with many chronic diseases, including autoimmune disorders. Studies have repeatedly shown an association between low vitamin D levels and increased incidence of several different autoimmune diseases including multiple sclerosis (MS), rheumatoid arthritis (RA), type 1 diabetes mellitus, inflammatory bowel disease (IBD), mixed connective tissue disease, autoimmune thyroid disease, scleroderma and systemic lupus erythematous. (Pelajo.C.F. et al, 2010, Cooper et al 2009\&Goodin DS.2014).

Vitamin D deficiency is a global health problem, its role as an immune modulator has been recently emphasized. The evidence is increasingly pointing towards vitamin D significant role in reducing the incidence of autoimmune diseases (Hussein.A.et al, 2013). Vitamin D has modulatory effects on B lymphocytes and Immunoglobulin production. Many immune cells contain vitamin D receptors including monocytes, macrophages, dendritic cells and activated $\mathrm{T}$ and $\mathrm{B}$ cells and these immune cells possess the enzymatic machinery, necessary to convert vitamin D into its active form. (Kamen DL and Tangpricha V, 2010. Hewison M.2012).As the vitamin D receptor is expressed on immune cells and these immunologic cells are capable of synthesizing the active vitamin D metabolite, Vitamin D can modulate the innate and adaptive immune responses. (Hossein-Nezhad, A., \& Holick, M. F. 2013). Risk factors for vitamin D deficiency are children of all ages, pregnant women,obese people, darker-skinned people,and the person of,mal-absorptionsyndrome, osteoporosis,osteomalacia, elderly, chronic liver failure, consuming anti- seizure medications, glucocorticoids and antifungal drugs (Holick MF,2007).

\section{Uses and Benefits of Vitamin D}

Young and unmarried individuals are more likely to have insufficient levels of vitamin D. Deficiency in vitamin D is associated with increased autoimmunity as well as an increased susceptibility to infection. The beneficial effects of supplementing vitamin D deficient individuals with autoimmune disease may extend beyond the effects on bone and calcium homeostasis. (HosseinNezhad. A. \& Holick.M. F.2013\&MarwaTaffaha et al.2015)

Adolescence group is viewed as an opportune time to practice healthy living habits and prevent future health complication. Studies have found that maintaining vitamin D status during childhood and adolescence may reduce ones risk of developing various diseases in future.(Fadia S. AlBuhairan.et al.2015).Vitamin D has several important functions. Perhaps the most vital are regulating the absorption of calcium and phosphorous and facilitating normal immune system function. Sufficient amount of vitamin D is important for normal growth and development of bones and teeth, as well as improved resistance against certain diseases. Vitamin D might play an important role in regulating mood and warding off depression. Scientists found that people with depression who received vitamin D supplements noticed an improvement in their symptoms. Researchers found vitamin D deficiency was more common in those who were experiencing anxiety and depression. The scientists said the extra calcium and vitamin D had an appetite suppressing effect that able to lose more weight(Holick2011). It was concluded that, a single dose of 100,000 IU vitamin D3 is an effective, well-tolerated, and economical treatment strategyfor healthy adults who report fatigue. (Tovey.A.Cannell.J.J, 2017) 


\section{International Journal of Science and Research (IJSR) \\ ISSN (Online): 2319-7064}

Index Copernicus Value (2015): 78.96 | Impact Factor (2015): 6.391

There are several studies recently conducted over 12000 adolescents in Saudi Arabia, to identify health risk behaviors and the health status in this population. Among them, 28\% of the adolescents reported having a chronic health conditions, $3 \%$ reported symptoms of depression, $30 \%$ were considered overweight or obese, and this is the largest study in Saudi Arabia, shockingly this research revealed, high prevalence of vitamin D deficiency as follows: $96 \%$ were vitamin D deficient, defined by levels less than $20 \mathrm{ng} / \mathrm{ml}$. (Al Buhairan, L. et al., 2015).Determinants often include, age, race, time spent outdoors, or sunlight exposure, geographic region of residence, season of blood draw, body mass index or body fatness, and physical activity. Hence we need to better understand intra-individual variation in $25(\mathrm{OH})$ concentrations among people and how this variability relates to disease status.Vitamin D helps fight diseases such as colon cancer, breast cancer, heart disease, Type II diabetes, and the common flu. He also pointed out that the recommended period for sun exposure to the sun is half-anhour, three to four days a week. (Al-Daggrey., 2014)

\section{Vitamin D and Protective Immunity}

Several factors affect your immune system, so take a comprehensive approach at keeping it running tip-top. There are relationships between low level vitamin $\mathrm{D}$ with single or multiple autoimmune diseases. Vitamin D levels would be determined from plasma samples obtained fromthe blood specimens to measure autoantibodies, serum IFN $\alpha$ activity and B cell activation (White, J.H.2012).

An autoimmune disorder may affect one or more organ or tissue types. Areas often affected by autoimmune disorders include: Blood vessels, Connective tissues, Endocrine glands such as the thyroid or pancreas, Joints, Muscles, Red blood cells, Skin. Autoimmune disease affects up to 50 million Americans, according to the American Autoimmune Related Diseases Association (AARDA). As a result, your immune system attacks healthy cells \& changes in organ function. There are as many as 80 types of autoimmune diseases. Many of them have similar symptoms, which makes them very difficult to diagnose. Vitamin $\mathrm{D}$ has been used to treat infections such as tuberculosis before the advent of effective antibiotics. Tuberculosis patients were sent to sanatoriums where treatment included exposure to sunlight which was thought to directly kill the tuberculosis. Cod liver oil, a rich source of vitamin D has also been employed as a treatment for tuberculosis as well as for general increased protection from infections(White, J.H.2012, Pelajo CF,etal., 2010\&Mora, J.R.etal., 2008)

The implications of vitamin D deficiency on the immune system have become clearer in recent years and vitamin D deficiency increasedthe susceptibility to infection and a diathesis, in a genetically susceptible host to autoimmunity. Many lifestyle and environmental factors can affect your ability to get sufficient amounts of vitamin D through the sun alone. These factors include: pollution, use of sunscreen, spending more time indoors, living in big cities where buildings block the sunlight, having darker skin. (Adams JS. \&Hewison M.2010). Vitamin D supplementation may be needed for the prevention of osteoporosis and for pain relief in patients with RA. (Kamen
DL, Tangpricha. 2010\& Pelajo CF, et al. 2010). Further to this, there is increasing epidemiologic evidence linking vitamin D deficiency and autoimmune diseases including multiple sclerosis (MS), rheumatoid arthritis (RA), diabetes mellitus (DM), inflammatory bowel disease and systemic lupus erythematosus (SLE).Lower maternal intake of vitamin $\mathrm{D}$ during pregnancy in women whose prospective child were at risk of developing autoimmune DM \&associated with increased risk of the child developing pancreatic autoimmunity. (Pelajo CF, etal.2010.Kriegel MA1, etal., 2011). In conclusion, it appears that vitamin D deficiency is highly prevalent in patients with RA\& linked to diffuse musculoskeletal pain.

Many malignant tumors including breast, lung, skin (melanoma), colon, and bone suggesting that they might be susceptible to the effects of vitamin Insulin-dependent diabetes mellitus (type 1 diabetes mellitus) and systemic lupus erythematous (SLE) are examples of autoimmune diseases. Autoimmune diseases occur when the body mounts an immune response against its own tissue, rather than a foreign pathogen. Type 1 diabetes mellitus, insulinproducing $\beta$-cells of the pancreas are the target of an inappropriate immune response. (Zahid etal.2011Tovey, 2017) suggested that, clinical trials are needed to determine, whether vitamin D supplementation may help prevent or improve outcomes for colorectal cancer patients. (Tovey.A.Cannell.J.J, 2017)

\section{Natural Sources of Vitamin D}

\begin{tabular}{|c|c|c|}
\hline Food & Amount & $\begin{array}{l}\text { 3 Daily } \\
\text { Value }\end{array}$ \\
\hline $\begin{array}{l}\text { Cod liver oil, } 1 \\
\text { tablespoon }\end{array}$ & $1360 \mathrm{IU} / 34 \mathrm{mcg}$ & $227 \%$ \\
\hline $\begin{array}{l}\text { Salmon, cooked, } 3 \\
\text { ounces }(85 \mathrm{~g})\end{array}$ & $447 \mathrm{IU} / 11 \mathrm{mcg}$ & $75 \%$ \\
\hline $\begin{array}{l}\text { Tuna, canned in water, } \\
3 \text { ounces }(85 \mathrm{~g})\end{array}$ & $154 \mathrm{IU} / 4 \mathrm{mcg}$ & $26 \%$ \\
\hline $\begin{array}{l}\text { Beef liver, cooked, } 3 \\
\text { ounces }(85 \mathrm{~g})\end{array}$ & $42 \mathrm{IU} / 1 \mathrm{mcg}$ & $7 \%$ \\
\hline $\begin{array}{l}1 \text { large whole egg ( } D \text { is } \\
\text { found in yolk) }\end{array}$ & $41 \mathrm{IU} / 1 \mathrm{mcg}$ & $7 \%$ \\
\hline $\begin{array}{l}1 \text { sardine, canned in } \\
\text { oil. drained }\end{array}$ & $23 \mathrm{IU} / 0.6 \mathrm{mcg}$ & $4 \%$ \\
\hline
\end{tabular}

Figure 1: Institute of Medicine, 2010

As shown at figure (1) Vitamin D is oil soluble, which means you need to eat fat to absorb it. Natural foods high in vitamin D include fish oils, fatty fish, mushrooms, beef liver, cheese, and egg yolks. In addition, vitamin D is widely added to many foods such as milk and orange juice, and can also simply be consumed as a supplement. Foods that contain vitamin D include:salmon,sardines,egg yolk,shrimp,milk(fortified), cereal(fortified),yogurt(fortified) ,orange juice(fortified).(Institute of Medicine, 2010.Holick MF.2011).

\section{Prevention of Autoimmune Diseases}

Osteoporosis is a disease of increased bone fragility, and it is a major cause of morbidity and economic burden worldwide. 


\section{International Journal of Science and Research (IJSR) \\ ISSN (Online): 2319-7064}

Index Copernicus Value (2015): 78.96 | Impact Factor (2015): 6.391

It is not restricted to adults, it can occur in children and adolescents. The recent exponential surge in vitamin D research for the past 10 years, reflect the global epidemic of vitamin deficiency and its potential impact on several chronic diseases in both children and adults. Still, a combination of baseline blood $25(\mathrm{OH}) \mathrm{D}$ concentrations and questions about lifetime dietary, supplemental, and sunlight exposure in estimating, vitamin $\mathrm{D}$ status for a longer duration, remain understudied (Neville H Golden and Steven A Abrams, 2013).

Figure (2) showed that obtaining a combination of sensible sun exposure along with adequate vitamin D supplementation for all children and adults will prevent vitamin $\mathrm{D}$ deficiency in the general population, maximizing bone health and reducing the risk of many chronic diseases associated with vitamin D deficiency. From birth and throughout childhood recommends 400 IU vitamin $\mathrm{D} /$ day. The Institute of Medicine (IOM) Older as well as adults receive $600 \mathrm{IU}$ of vitamin D a day. For children older than 8 years old and all adults the upper limit has been raised to 4000 IU of vitamin D a day.Institute of Medicine (IOM, 2010).

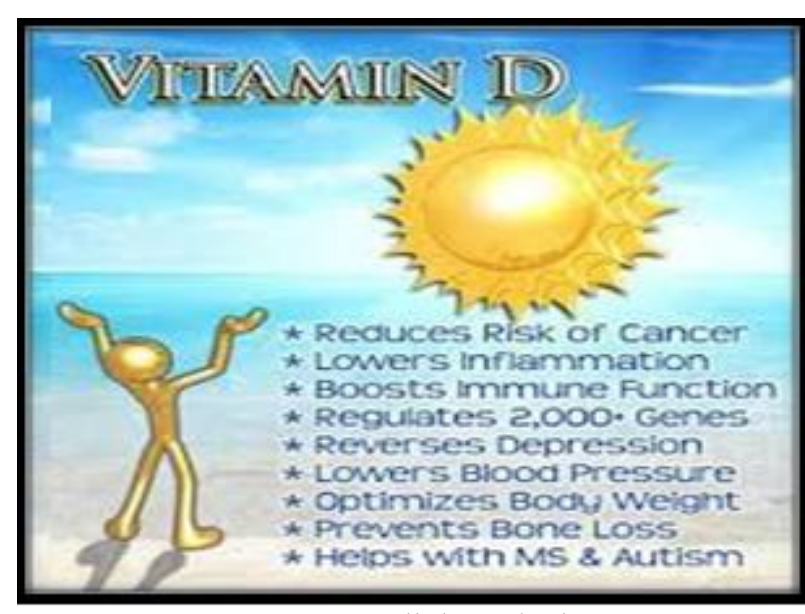

Figure 2: Sunlight and Vit D

\section{Recommended Dietary Allowance of Vitamin D}

There has been some controversy over the amount of vitamin D needed for healthy functioning.Figure (3) showed daily requirement of vitamin $\mathrm{D}$ should be from 400 to 800 IU in all ages, and especially, from age of a few years old to over 70 years, it should be at least 800 IU. The minimum vitamin $\mathrm{D}$ intake should come from a blood test given in the fall or winter. (Institute of Medicine, 2010 \&Holick MF.2010).

\begin{tabular}{|c|c|c|c|c|}
\hline 소를 & Male & Female & Pregnamey & Lactation \\
\hline D-12 mombst & $\begin{array}{c}40011 \\
010 \text { mag) }\end{array}$ & $\begin{array}{r}4001 \mathrm{I} \\
\text { 10mes }\end{array}$ & & \\
\hline 1 - 3 years & $\begin{array}{l}\operatorname{cog} 1 \mathrm{U} \\
1 \mathrm{mcg}\end{array}$ & $\begin{array}{l}6001 \square \\
15 \operatorname{mac}\end{array}$ & & \\
\hline $14-1 \mathrm{~s}$ years & $\begin{array}{l}\text { 600 1U } \\
15 \text { meg }\end{array}$ & $\begin{array}{l}60010 \\
15 \operatorname{mos}\end{array}$ & $\begin{array}{l}60010 \\
11 \mathrm{mcg}\end{array}$ & $\begin{array}{l}600 \mathrm{~mL} \\
115 \mathrm{meg}\end{array}$ \\
\hline $19-50$ years & $\begin{array}{c}\text { coo 1u } \\
\text { [15 mase }\end{array}$ & $\begin{array}{r}\text { 600 } 1 \mathrm{U} \\
15 \text { meg }\end{array}$ & $\begin{array}{c}600 \text { IU } \\
15 \text { mise }\end{array}$ & $\begin{array}{l}50010 \\
13 \text { racal }\end{array}$ \\
\hline $51-70$ gears & $\begin{array}{l}6001 \mathrm{U} \\
115 \mathrm{meg}\end{array}$ & $\begin{array}{l}6001 \square \\
15 \mathrm{mcz}\end{array}$ & & \\
\hline$=70$ years & $\begin{array}{l}\text { g00 IU } \\
\text { 20 mcg }\end{array}$ & $\begin{array}{r}9001 \mathrm{U} \\
\text { ID megl }\end{array}$ & & \\
\hline
\end{tabular}

Figure 3: Daily Dietary Allowance of Vitamin D

It is currently agreed that the measurement of total serum 25-hydroxyvitamin D concentration $(1 \mathrm{ng} / \mathrm{mL}$ corresponding to $2.5 \mathrm{nmol} / \mathrm{L}$ ) is the best indicator to evaluate vitamin $\mathrm{D}$ status. The World Health Organization (WHO) and the review undertaken to inform the new Nordic Nutrition Recommendations, NNR 2012, (Nordic Councils of Ministers 2014) have also defined vitamin D insufficiency as a serum $25(\mathrm{OH})$ D below $50 \mathrm{nmol} / \mathrm{L}$ with Serum $25(\mathrm{OH}) \mathrm{D}$ below $25 \mathrm{nmol} / \mathrm{L}$ considered to indicate Deficiency. (WHO Scientific group on the Prevention and Management of Osteoporosis 2003; Lamberg-Allardt et al.2013). However, high-quality evidence is still needed to ensure that the current cutoff values, which is optimal to define states of deficiency.(Raimondi et al 2009,Holick MF et al 2011,Goodin DS, 2014))

\section{Health education on healthy lifestyle intervention and Oral vitamin D Supplementation}

According to Recommendations for vitamin intake, endorsed by the Institute of Medicine, the Endocrine Society and the American Academy of Pediatrics, suggest monitoring 25(OH)D levels among periodically, and initiating treatment if levels fall below $20 \mathrm{ng} / \mathrm{ml}(50 \mathrm{nmol} / \mathrm{L})$. US national institute of health (updated 2014) recommend the daily intake of vitamin D, 400 IU for adolescents, it would also be decided upon their other sources of daily intake of vitamin D.Lifestyle intervention would bring, the knowledge about the sources of vitamin D for their better health to prevent them from suffering with vitamin $d$ deficiency related diseases and complications in their lifetime. 


\section{International Journal of Science and Research (IJSR) \\ ISSN (Online): 2319-7064 \\ Index Copernicus Value (2015): 78.96 | Impact Factor (2015): 6.391}

\section{Summary\& Conclusion}

Studies have repeatedly shown an association between low vitamin D levels and increased incidence of several different autoimmune diseases. Vitamin D may reduce inflammation and help prevent autoimmune diseases, including rheumatoid arthritis \&multiple sclerosis. However, further high-quality research is needed to confirm these results. Establishing patterns of coexistence between autoimmune diseases may inform better classification of this set of diseases, and it may provide important clues as to their pathogenesis. Vitamin D plays an important role in many places throughout the body, including the development and calcification of the bones. Adequate exposure to sunlight and the use of dairy products with vitamin $\mathrm{D}$ have significantly reduced the incidence of vitamin D deficiency. Vitamin D is unique among vitamins; you can synthesize it in your skin as well as absorb it from foods or supplements. Your skin synthesizes vitamin D3, also called cholecalciferol. Spending more time in the sun \& taking supplements can help raise D3 level, which is measured by checking 25-hydroxyvitamin D, or $25(\mathrm{OH})$ D levels. 25hydroxyvitamin D. Scientific evidence indicates that calcium and vitamin D play key roles in bone health. The following is lists of things you can do to alleviate the symptoms of an autoimmune disease include: eat a balanced and healthy diet, exercise regularly, get plenty of rest, take vitamin supplements, decrease stress, sun exposure, and avoid any known triggers of flare-ups.

\section{References}

[1] Pelajo CF, Lopez-Benitez JM, Miller LC. Vitamin D and autoimmune rheumatologic disorders. Autoimmune Reviews, Johns Hopkins University, 2010,9(7),507-510. Cooper.

[2] Marwa Tuffaha, Charbel El Bcheraoui, Farah Daoud, Hessah Abdulla Al Hussaini, Fahad Alamri,Mohammad Al Saeedi, Mohammed Besulaiman, Ziad A Memish, Mohammad A AlMazroa, Abdullah A Al Rabeeah, Ali H Mokdad. (2015)Deficiencies under plenty of sun: Vitamin D status among adults in the kingdom of Saudi Arabia. North American Journal of Medical Sciences; 7(10), 467-475.

[3] G.S., Bynum.M.L, Somers.E.C.Recent insights in the epidemiology of autoimmune diseases, improved prevalence estimates and understanding of clustering of diseases. Auto immunology,2009,33(3-4):197-207.

[4] Goodin DS. The epidemiology of multiple sclerosis: insights to disease pathogenesis. HandbClin Neurol. 2014; 122:231-266.

[5] Hossein-Nezhad, A., \& Holick, M. F. (2013). Vitamin D for health: A global perspective. MayoClinical Proceedings, 88(7),720-755.

[6] Kriegel MA1, Manson JE, Costenbader KH. 2011: Does vitamin $\mathrm{D}$ affect risk of developing autoimmune disease? A Systematic review.Seminars inArthritis\& Rheumatism. 2011,40(6): 512-531.

[7] Kamen DL, Tangpricha V. Vitamin D and molecular actions on the immune system: modulation of innate and autoimmunity. Journal of Molecular Medicine. 2010;88:441-50
[8] Hewison M. An update on Vitamin D and human immunity, clinical Endocrinology, 2012, volume 76, Page 315-325.

[9] Tovey.A, Cannell.J.J, Vitamin D improves fatigue, according to new study, The vitamin D council Blog\&Newsletter, 2017.

[10] White, J.H. Vitamin D metabolism and signaling in the immune system. Rev. Endocrinology Metabolism Disorder. 2012, 13, 21-29.

[11] Adams.J.S, Hewison.M.2010, Update in Vitamin D.Journal of clinical Endocrinology Metabolism.95:471-478.

[12] Tovey.A.Cannell.J.J, Meta-analysis finds vitamin D is inversely associated with colorectal cancer risk. The vitamin D council\& Newsletter, 2017.

[13]ZahidNaeem,AbdulRahmanAlMohaimeed,FawzyKhalil SharafIsmail,FaizaShaukat\&SNNazmiInam,Vitamin D status among population of Qassim region,SaudiArabia, International journal of Health sciences, Volume.5(2),2011:116-124

[14] Institute of Medicine, Food and Nutrition Board. Dietary Reference Intakes for Calcium and Vitamin D. Washington, DC: National Academy Press, 2010.

[15] Raimondi S, Johansson H, Maisonneuve P, Gandini S. Review and meta-analysis on vitamin $\mathrm{D}$ receptor polymorphisms and cancer risk. Carcinogenesis. 2009; 30(7):1170-1180.

[16] AgmonLevin.N. Mosca.M.Shoenfeld.Y. Systemic lupus Erythematous one disease or many? Auto immunity reviews, Johns Hopkins University,2012,11(8):593-595.

[17] Cynthia Arnow 2011. Vitamin D and the Immune System, Journal oflnvestigative Medicine. 2011, volume, 59(6): 881-886.

[18]Fadia S. AlBuhairan, Hani Tamim, Mohammad Al Dubayee, Shahla AlDhukair, Sulieman Al Shehri, Waleed Tamimi, Charbel El Bcheraoui, Mohi Eldin Magzoub, Nanne de Vries, Ibrahim Al Alwan, 2015, Time for an adolescent Health Surveillance system in Saudi Arabia, Journal of adolescent health, 57, 263-269.

[19] Holick MF, Binkley NC, Bischoff-Ferrari HA, et al. Evaluation, treatment, and prevention of vitamin D deficiency: an Endocrine Society clinical practice guideline. Journal ofClinical Endocrinology Metabolism. 2011;96(7):1911-1930.

[20] Walker.V.P, Modlin.R.L. The vitamin D connection to pediatric infections and immune function. https://www.ncbi.nlm.nih.gov/pubmed/19190532 